\title{
Buprenorphine Transdermal Matrix Patch
}

National Cancer Institute

\section{Source}

National Cancer Institute. Buprenorphine Transdermal Matrix Patch. NCI Thesaurus. Code C85483.

A transdermal matrix patch containing the synthetic opioid buprenorphine with analgesic and sedative activities. Buprenorphine binds to and activates the mu-opioid receptors in the central nervous system (CNS), thereby mimicking the effects of the endogenous opiates. Binding to opioid receptors stimulates exchange of GTP for GDP, inhibits adenylate cyclase, and decreases intracellular cAMP. This inhibits the release of various nociceptive neurotransmitters, such as substance $P$, gamma-aminobutyric acid (GABA), dopamine, acetylcholine, noradrenaline, vasopressin, and somatostatin. In addition, buprenorphine closes $\mathrm{N}$-type voltage-gated calcium channels and opens calciumdependent inwardly rectifying potassium channels, resulting in hyperpolarization, reduced neuronal excitability, analgesia and sedation. Buprenorphine is a partial agonist at the mu-opioid receptor and an antagonist at the kappa-opioid receptor in the CNS. 